\title{
Una réplica a la Encyclopédie méthodique: la Defensa de Barcelona
}

\author{
FRANCISCO LAFARGA \\ Universidad de Barcelona
}

El artículo «Espagne» publicado por Masson de Morvilliers en la Encyclopédie méthodique provocó, como es sabido, una de las polémicas culturales más célebres del siglo XVIII español y originó un verdadero conflicto diplomático entre Francia y España.

De no haber contenido el mencionado artículo distintas proposiciones que se consideraron atentatorias al «honor nacional», la Encyclopédie méthodique hubiese tal vez podido circular libremente por España. Ya en 1782, poco tiempo después de anunciada su publicación en Francia, se abrió una suscripción en España, encabezada por el propio Inquisidor general, don Felipe Bertrán ${ }^{1}$. Los suscriptores llegaron a

1 Sobre este tema véase especialmente Gonzalo Anes, «La "Encyclopédie méthodique"' en España», en Ciencia social y análisis económico. Estudios en homenaje al profesor Valentín Andrés Alvarez, Madrid, 1978, pp. 105-152. Tambien Luigi Sorrento, Francia e Spagna nel Settecento. Bataglie et sorgenti di idee, Milán, 1928, pp. 89-111, y Richard Herr, España y la revolución del siglo XVIII, Madrid, 1964, pp. $182-189$. 
330, aunque su identidad no nos es conocida; se obtuvo el permiso de importación y se procedió a distribuir los primeros tomos de la obra, con el beneplácito del Consejo de Castilla, presidido interinamente a la sazón por Campomanes, y del conde de Floridablanca, ministro de Estado. Pero cuando el tomo de geografía llegó a España provocó tal escándalo que llegó hasta los aposentos de Carlos III en El Escorial.

Comenzó entonces un largo proceso en el que se vieron involucrados la Inquisición, el Consejo de Castilla, el ministerio de Estado y el librero francés Panckoucke, a través de su agente en Madrid. Tras un tira y afloja entre la Inquisición y el Consejo de Castilla, el Santo Oficio consiguió, en 1788, la incautación de los tomos de la Encyclopédie que habían llegado a Madrid mientras se realizaban las enmiendas oportunas..., enmiendas que nunca se llevaron a término sobre la edición francesa, ya que en el mismo año de 1788 el editor madrileño Antonio de Sancha presentaba a la Inquisición diversos tomos traducidos de la Encyclopédie antes de su publicación (algo totalmente insólito) para obtener el visto bueno del Santo Oficio y evitar riesgos una vez editada la obra, aunque sólo aparecieron diez volúmenes, entre 1788 y $1794^{2}$.

Al margen de este episodio, que pone de manifiesto un conflicto de competencias entre los Consejos de Castilla y de Inquisición, así como la rivalidad entre Campomanes y Floridablanca, queda del asunto copiosa literatura apologética. Son conocidas las defensas escritas en París por Antonio José Cavanilles, alentado y socorrido por la embajada española ${ }^{3}$, en Berlín por el abate italiano Carlo Denina ${ }^{4}$ y en Madrid por Juan Pablo Forner ${ }^{5}$, incansable polemista que por su virulencia dio pie a réplicas y contrarréplicas publicadas en opúsculos y diarios.

2 Fueron los siguientes: Gramática y literatura (vol. I), trad. por Luis Mínguez de San Fernando; Historia natural de los animales (II), trad. por Gregorio Manuel Sanz y Chávez; Historia de las aves (III), trad. por Joseph Mallent; Arte militar (IV y V), trad. por Luis Castañón; Geografía (VI y VII), trad. por Juan Arribas y Julián de Velasco; Artes académicas (VIII), por Baltasar de Irurzun (Arte de la equitación) y Gregorio Manuel Sanz (Arte de bayle, esgrima y nadar); Artes y oficios (IX y X), por Antonio Carbonell.

3 A. J. Cavanilles, Observations de M. l'Abbé Cavanilles sur l'article Espagne de la Nouvelle Encyclopédie, París, 1784. Antes de finalizar el año apareció en Madrid una edición española.

4 C. Denina, Réponse d̀ la question Que doit-on à l'Espagne? Discours lu à l'Assemblée publique de 26 janvier de l'an 1786 pour le jour anniversaire du Roi, Berlín, 1786. El discurso, leído en la Academia de Ciencias de Berlín, fue publicado el mismo año en castellano en Madrid, acompañando a la Oración apologética de Forner.

5 J. P. Forner, Oración apologética por la España y su mérito literario; para que sirva de exornación al discurso leido por el Abate Denina en la Academia de Ciencias de Berlín, respondiendo a la qüestion ¿Qué se debe a España?, Madrid, 1786. El 
En esta línea se encuentra el texto que traemos aquí a colación, la Defensa de Barcelona, publicada por Mariano Berlon en el Memorial literario de junio de $1787^{6}$. Dicha defensa, escrita en forma de carta a los redactores del periódico, es posterior a la publicación de las obras ya citadas de Cavanilles, Denina y Forner, y participa en cierto modo de su indignación y de su deseo de enmendar los yerros y disparates que se hallan en la Encyclopédie méthodique.

La Defensa de Barcelona es, pues, mucho más que un alegato contra las inexactitudes y errores observados en el correspondiente artículo de la enciclopedia francesa: el autor arremete en ella contra Masson de Morvilliers, señalándole como el preguntador famoso de «¿Qué se debe à la España?», poniendo de manifiesto su escasa información sobre Barcelona y los errores que escribe sobre esta ciudad, que no pueden pasar desapercibidos a ninguno de sus habitantes. La crítica tiene un alcance mayor, ya que el autor de la Defensa pone en tela de juicio no sólo la veracidad y buena fe de Masson, sino de toda la Encyclopédie, obra a la que al principio califica de «sublime» y de «depósito de los conocimientos humanos». Y aún más, lleva el tema hasta las relaciones entre las naciones y los pueblos, insistiendo en el poco aprecio de los franceses por los españoles en el siglo XVIII.

Se transcribe a continuación el texto de la Defensa de Barcelona, acompañado de notas aclaratorias. Conviene señalar que años más tarde, en 1792, aparecieron los dos volúmenes dedicados a Geografía en la versión castellana de la Encyclopedia metódica, y que en el artículo Barcelona (vol. I), después de traducir el texto de la edición original francesa, el traductor Julián de Velasco añade otro que quintuplica la longitud del primero y muy bien hubiese podido publicarse en lugar de aquél. Parece seguir en esto, amén del tono general de la obra, la opinión de su colaborador en la traducción y arreglo de los tomos de geografía, Juan de Arribas y Soria, que en 1784 había sido nombrado por el Consejo de Castilla censor de la edición francesa para dicha materia y que en su informe de 16 de agosto de 1785 declaraba que los mencionados tomos estaban plagados de errores y aconsejaba que «todo lo de Geografía se suspendiese enteramente y (se ordenase) que un cuerpo de sabios, como el de la Historia u otro, formase los artículos pertene-

mejor estudio sobre la Oración, sus antecedentes y sus consecuencias se halla en François Lopez, Juan Pablo Forner et la crise de la conscience espagnole, Burdeos, 1976, pp. 371-436.

6 M. Berlon, Defensa de Barcelona contra la descripción poco exâcta y veridica que de dicha Ciudad hace Mr. Masson en el tomo I de la Geografia moderna de la Encyclopedia metodica francesa, Memorial literario de junio de 1787, pp. 182-194. 
cientes a la Geografía de España», que se enviaran éstos a París, se tradujesen al francés y se insertasen en todos los ejemplares destinados al extranjero?.

En la «Advertencia del editor» que precede a los artículos de geografía en la versión española puede leerse: «Hemos procurado en la traducción que se publica mejorar notablemente el original, y se han añadido innumerables artículos de España y América, en que la poca instruccion de los Autores franceses sobre nuestras cosas, ó sea el poco caso que hacen de ellas, ha dexado vacíos y errores de mucha consideración que hemos procurado enmendar del mejor modo posible» ${ }^{8}$.

\section{Defensa de Barcelona contra la descripcion poco exâcta y veridica que de dicha Ciudad hace Mr. Masson en el tomo I de Geografia moderna de la Encyclopedia metodica Francesa}

Muy Sres. mios: á tiempo que estaba leyendo en el Memorial Literario del mes de Febrero de este año el artículo que habla de la poblacion de Barcelona ${ }^{9}$ me presentaron de parte de un amigo el tomo I de la Geografia de la famosa Enciclopedia metodica francesa $a^{10}$. Recibí este libro como la cosa mas preciosa, y que hacia mucho tiempo deseaba. ¡Que nociones no me prometia adquirir en esta sublime obra que creia como el deposito de los conocimientos humanos! ¡Encyclopedia metodica francesa! Discurran Vms. con que furor la desfloraría mi solicitud, y con que exâctitud pensaria hallar todos los articulos en un libro que disfruta los mayores elogios de sus paisanos, y que lleva á la frente el sello nacional.

7 A. H. N., Consejos, legajo 1965 , expediente n. ${ }^{\circ} 34$, pieza $1 .^{a}$, folios 131-132. Cit. por G. Anes, op. cit., pp. 137-138.

8 Encyclopedia metódica. Geografía moderna, traducida del francés al castellano por los Señores Don Juan Arribas y Soria, y Don Julián de Velasco, Madrid, Imprenta de Sancha, MDCCXCII. El artículo «Barcelona» ocupa las pp. 258 a 262 del tomo I.

9 Se refiere a unas Memorias de la Ciudad de Barcelona, publicadas por Francisco de Zamora y Ayllón, alcalde del Crimen de la Real Audiencia de Barcelona, en el Memorial literario de febrero de 1787, pp. 175-178. Este breve resumen del estado de Barcelona en mayo de 1786 fue utilizado asimismo por Julián de Velasco en su artículo citado de la Encyclopedia metódica, p. 260 a.

10 El autor de la Defensa fue en realidad uno de los escasos españoles que tuvieron acceso a la Encyclopédie méthodique, de la que se distribuyeron poquísimos ejemplares (cfr. G. Anes, op. cit., p. 152); aunque también es posible que el amigo que facilitó la obra a Berlon la obtuviese por otro conducto. 
Ya se ve, yo soy un Español ramplon y de quatro suelas, y luego fixé mi atención en lo que trata de mi casa. ¿Creerian Vms. que aun no he vuelto de mi sorpresa quando leí el artículo de Barcelona, que fue el primero que picó mi curiosidad? Dignense Vms. notar (y que no se les olvide) que este artículo va señalado con las letras M. D. M. que significan que su autor es Mr. Masson de Morvilliers, á cuyo cargo está la Geografia moderna. No se acuerdan Vms. de un terrible preguntador, que no logrando otras luces que las que le comunica su malicia, preguntaba: ¿Qué se debe á la España? Pues este Mr. Geografo moderno es el mismo que ha compuesto el artículo de Barcelona, y el que habla de esta ilustre Ciudad tan cortamente, como si hablara de los Paises imaginarios, $y$ aun puede ser que de estos en fuerza de los grandes paseos que hacen por el aire sus hermanos, le habrian dado noticias más dilatadas. Yo me escandalizo, Señores, quando veo la torpe y afectada ignorancia de unos hombres destinados á componer una obra que va á ser la admiracion del Universo. Si se hablara de los paises interiores de la China, disimularia su flaqueza, pues pensaría que sus viageros aëreos aun no han vuelto de sus utiles expediciones ${ }^{11}$. Pero ahora tratamos de un Reyno vecino, y de una Capital de la frontera, que quando no fuese por la horrorosa constelación de sus hermanos, á lo menos por tantos libros que tratan de esta Ciudad, podia Mr. Masson Geografo moderno hacer una descripcion mas exâcta y veridica de ella.

¿Y esta es la sublime obra nacional que será el monumento mas glorioso del siglo XVIII? ¿Pues qué es lo que se debe á la Francia? Por lo general una confusísima multitud de escritores copistas, sin critica, sin gusto, y sin conocimiento de lo que escriben, cuyo carácter no es otro que la satira, la maledicencia y la denigracion de sus mismos amigos $^{12}$. Yo no hallo disculpa en este Mr. Preguntador y Geografo moderno. Aun quando hubiese emprendido la Geografia antigua, hubiera hallado infinitos monumentos que le convencerian que Barcelona desde que es Barcelona ha sido una Ciudad tan gloriosa, tan ilustre, tan laboriosa y tan comerciante como la que mas de Francia. No puedo convencerme de que este Geografo moderno lo sea tanto, que ignore

11 Alusión a los numerosos viajes «filosóficos» y utopías publicados en Francia (y en otros paises) durante el siglo XVIII.

12 «Este es el genio del siglo... Cuatro donaires, seis sentencias pronunciadas como en la trípode, una declamación salpicada de epigramas en prosa, cierto estilo metafísico sembrado de voces alusivas a la Filosofía con que quieren ostentarse filosofos los que tal vez no saben de ella sino aquel lenguaje impropio y afectado, se creen suficientes para que puedan compensar la ignorancia y el ningún estudio». J. P. Forner, Oración apologética, op. cit., p. 11. 
estas cosas tan sabidas de las Naciones mas remotas. Solo la malicia es capaz de producir unos hombres tan cortos ${ }^{13}$. Pues ¿qué le ha hecho la España para que la quiera degradar tanto de su gloria? ¿Qué, porque su sabio gobierno impide el ingreso á esta charlataneria de Autores impios que atacan la Religion, destruyen la autoridad pública, é igualan los hombres á las bestias?

La España, la sabia y profunda España goza con abundancia todas las obras necesarias para formar hombres grandes; pero no tiene el prurito de escribir bagatelas ni libros perniciosos que insulten á las mismas testas coronadas. La España, en las producciones de su país da de comer á sus vecinos, y estos la retribuyen con la maledicencia. La España, en todos tiempos ha hecho justicia á las luces y al mérito de los Franceses, y estos mayormente en los dias presentes, tienen la bondad de pintarla como una tierra que no produce sino estolidez, pereza y holgazaneria ${ }^{14}$. Ilustres Españoles, no envidiemos la suerte á los demas vivientes: contentemonos con nuestros conocimientos, y llenemos de bendiciones al cielo por mantenernos felices bajo la benefica sombra del buen Padre nuestro Augusto Soberano. El tierno amor que profeso á mi Nacion, dirige mi pluma, y aunque mi idioma es diferente del de la Corte, yo soy Español, y en esto constituyo mi dicha.

Barcelona, dice Mr. Masson, es una Ciudad situada á la orilla del Mar en forma de media luna. Es falso, que en la Geografia moderna tenga tal construccion: es un poligono regular ${ }^{15}$, y esta figura (que lo digan los Matematicos Franceses) es bien diferente de aquella. Dice, que se divide en alta y baja: es engaño, que, gracias á Dios, no hemos conocido los terremotos, y el terreno conserva desde que se fundó, la superficie casi igual ${ }^{16}$. El sitio de la Catedral si que está en una pequeña

13 En el momento de colaborar en la Encyclopédie méthodique, Nicolás Masson de Morvilliers (1740?-1789) había publicado, entre otras obras geográficas, un Abrégé de la géographie de l'Espagne et du Portugal (1776). Poeta mediocre, fue apreciado en su época como erudito y estudioso y ocupó algunos cargos públicos.

14 Así describe a los españoles Montesquieu en la $78^{\text {a }}$ de sus Lettres persanes, cuya refutación española se atribuye a Cadalso. Cfr. José de Cadalso, Defensa de la nación española contra la "Carta persiana $L X X V I I I »$ de Montesquieu. Edición de Guy Mercadier, Toulouse, 1970. Son conocidas las opiniones de Voltaire sobre España, recogidas últimamente por Manfred Komorowski, Das Spanienbild Voltaires, Frankfurt, 1976.

15 «No tiene la forma de media luna, como dice el Señor Masson, y sí es mas bien un ovalo irregular», Encyclopedia metódica. Geografía moderna, tomo I, p. 259 a.

16 «En quanto a su división en alta y baxa ya no se conoce, pues estan arruinadas las murallas que la ocasionaban, y en su lugar se han edificado casas, que hacen una toda la población», Encyclopedia metódica, op. cit., p. 259 a. 
elevación, y en lo restante todo observa una misma altura. Es de admirar que debiendo hablar el Señor Masson de lo moderno, no se digne advertir que la fortificacion de Barcelona es una de las mas bellas de Europa, y que merece la atencion de todos los ingenieros viajantes. El fuerte de Montjuich no está á la parte de poniente de la Ciudad, como lo expresa; pues en la Geografia moderna no ha variado el curso del sol, y se halla á la de medio dia, debiendo notar este Mr. que su fortaleza es magnifica en todas sus partes ${ }^{17}$.

Sino fuera por interrumpir el hilo de la narracion, haria ver que Mr. Masson encaja algunas mentirillas in facto propio. Por exemplo: se inititula Geografo moderno, y á fe que es rancio; la razon es, porque á la Real Audiencia la nombra casa de la Diputacion, que ha mas de 72 años que no existe, y que se le varió el nombre. Nota que en Barcelona hay Universidad, que igualmente hace ya 71 años que no la tiene, y es imposible que ningun extrangero curioso ignore que aquella desde el año 1716 se halla en Cervera ${ }^{18}$. Expresa igualmente, como una cosa notable, que en las Reales Atarazanas se construyen las Galeras del Rey, siendo la verdad que ni en España hay mas de quatro, y que no pasan de tres años de edad, y que ningun hombre las ha visto construir en todo este siglo en Barcelona ${ }^{19}$.. A mas de lo dicho, pone tambien como cosa particular el Arsenal de la Marina. Confieso que no sé en donde para, y creere que es alguna qualidad oculta en la imaginacion del Señor Geografo.

Esto es una prueba convincente de que este Mr. es un Empirico copista que no tiene conocimiento de lo que trata, y que pone solamente lo que halla en algunos Autorcillos decrepitos, que escribieron solamente por escribir como hace el. ¿Y estos son los que deben formar el deposito de los conocimientos humanos? ¿Y conocerán muchas verdades los hombres con unas noticias tan exâctas? ¿Qué se deberá á la Francia? Corrobora lo mismo el decir que la casa de la Diputación se halla adornada con un bello portico. Jamas ella lo ha tenido, y este que

17 «Al mediodia de Barcelona hay un pequeño puerto [...]. El monte Monjui lo abriga de los vientos ouestes por la parte occidental, y su cumbre está guarnecida de artilleria para seguridad del puerto. Esta montaña enriscada y escabrosa tiene un castillo al Occidente de la Ciudad, fortificado á lo moderno», Ecyclopedia metódica, op. cit., p. 259 b.

18 «La Universidad que dice el articulo que exîste hoy en Barcelona se trasladó a Cervera por decreto de Don Felipe V de 11 de mayo de 1717», Encyclopedia metodica, op. cit., p. 259 a.

19 «Ya no se construyen galeras en la atarazana de un siglo a esta parte, y hoy está destinada a fábricas de pertrechos y máquinas de guerra y principalmente de cañones y morteros», Encyclopedia metódica, op. cit., p. 259 a. 
efectivamente debe celebrarse se halla en la Iglesia parroquial de San Jaime, y no en la antigua Diputacion, en el dia Tribunal de la Real Audiencia. Se esfuerza mas la antiguedad de su escritorio con lo del magnifico salon, que supone en la misma. Hace muchos años que el mal humor de algun hombre tetrico, y que no conocia el mérito de esta fábrica, destruyó este monumento precioso, y que privó á la España de una pieza digna de la admiracion de todos los curiosos. En el diase ve reducida á varias piezas, que las mas sirven para habitacion del Regente de esta Audiencia. Gracias á la prudencia y habilidad de los Artifices, que supieron disponerlo de modo que con poco trabajo puede recobrar su primitiva forma; pues su construccion moderna es por medio de tabiques.

Entre las muchas plazas públicas que distingue Mr. Masson, pone con particularidad la de San Miguel, en la que supone que van á desembocar todas las principales calles de la Ciudad. Confieso mis cortas luces; pues aunque natural, no he hallado esta plaza; y por ahora me atrevo á desengañarle que no existe ${ }^{20}$. Parece que aun en aquellos poquísimos puntos en que quiere ostentar su liberalidad, ha hecho voto de ponernos las mas clasicas equivocaciones.

El Puerto, continua nuestro buen amigo, es largo y espacioso, defendido de un gran Dique. Le damos las mas tiernas gracias por su generosidad, y le confesamos sencillamente que nuestro puerto es uno de los mas infelices, y que todos los dias nos ofrece las mas funestas desgracias por su mala situacion ${ }^{21}$. A lo menos, puede ser que lo diga como un aguero feliz de lo que tantos años hace suspiramos.

A mas de la Academia de buenas Letras que dice Mr. Masson, que hay en Barcelona, le hacemos saber que posee la de Ciencias Naturales y Artes, la de Medicina, la de Jurisprudencia teorico práctica, y otros muchos establecimientos literarios, que son el honor de esta Capital, y un autentico testimonio de quanto se desvela el Gobierno en fomentar y proteger los adelantamientos nacionales. Es innegable que este Principado ha tenido sus Condes particulares hasta el siglo XII, en el que por el casamiento del Conde Ramon Berenguer con la hija del Rey Ramiro de Aragon se unió este Condado con aquella Corona; pero note el

20 «Lo que dice de la plaza de San Miguel no es cierto, pues esta plaza es poco digna de atención, y acaso querría el Señor Masson hablar de la de San Jayme, en donde en efecto van á parar muchas calles de la Ciudad», Encyclopedia metódica, op. cit., p. 259 a.

21 «Al Mediodía de Barcelona hay un pequeno puerto que solo admite embarcaciones de porte de 30 cañones», Encyclopedia metódica, op. cit., p. 259 b. 
Mr. literato, que el tal Conde fue Ramon IV y no V, que aun no le hemos conocido.

Si los Franceses quisieran tomarse la molestia de leer las obras exquisitas de los Españoles, sabrian con mas entereza nuestras cosas. Ya no pueden decir que no se escribe en España ${ }^{22}$; lo que han de expresar es que no quieren valerse de sus escritos, y que son como unos fenómenos raros los que conocen en Francia la delicadeza y magestad de nuestro precioso idioma. Si se dignasen hacerlo, entonces veriamos unas descripciones exâctas de nuestro pais, y sabrian que no debemos envidiar sus producciones. Esta es la causa de que en la Encyclopedia metodica francesa no se vea la menor particularidad de Barcelona. No me detengo en hacer una difusa analisis de esta Ciudad, pues los Españoles saben su estado floreciente, su laboriosidad, su comercio, su hermosura y su riqueza.

Pero lo que me ha exâltado mas el mal humor, y que no se lo puedo tolerar al Mr. Geografo moderno, es la grande satisfaccion con que asegura que la poblacion de esta numerosa Capital asciende á cerca de 16.000 personas. Se calcula, aunque no en un punto el mas fixo, que en Barcelona hay pasados de 111.000 almas ${ }^{23}$; y para su convencimiento apuntaré algunas pruebas. Barcelona tiene pasados de 94 Gremios y Colegios, sin una multitud de oficios que no se hallan incorporados en alguno de aquellos. En el año de 78 se publicó un librito con el título de Barcelona en la mano ${ }^{24}$, en el que se da un estado general de todos. Es verdad que es bastante diminuto, pues faltan en él muchísimos indivíduos por haberse sacado las noticias de la casa de la Ciudad, en la que solo se hallaban notados los que estaban sugetos á los pagamentos y demas contribuciones Reales. Desengañará aun mas al Mr. Preguntador Geografo el grande número de cabezas de ganado lanar, pelo y cerda que se han muerto en la propia Ciudad para su abasto desde el dia $1 .^{\circ}$ de Pasqua de Resurreccion de 1786 al Sabado Santo inclusive de 1787.

22 Juan Sempere y Guarinos había emprendido en 1785 la publicación de su Ensayo de una biblioteca española de los mejores escritores del reynado de Carlos III, Madrid, 1785-1789, que pretendía dar a conocer los progresos culturales realizados en España en la segunda mitad del siglo XVIII.

23 La misma cifra da la Encyclopedia metódica, p. 260 a, pues ambos autores la habían tomado de la Memoria de Francisco de Zamora ya citada, publicada en el Memorial literario de febrero de 1787.

24 Se trata de Barcelona à la mano, Compuesto por Don Joseph Algava Marques y Bellon, natural de la ciudad de Alcaras en Castilla la Nueva y residente en esta capital, Barcelona, 1778. En esta obra, además de dar el autor la lista de calles, gremios y conventos e iglesias, saca el cómputo de sus habitantes, que ascienden a 98.447. 
Segun el calculo mas exâcto que se ha hecho de cinco años á esta parte, consume esta Ciudad anualmente en pan para la subsistencia de su numeroso vecindario $\mathbf{8 8 5 . 0 0 0}$ fanegas de trigo. Creame en buena fe Mr. Masson: en Francia, excepto Paris se hallan muy pocas Ciudades de tanta poblacion como Barcelona.

Ultimamente concluye Mr. Masson su artículo, diciendo que el Obispo de esta Ciudad es sufraganeo del de Tarragona, y que en Barcelona se fabrican mantas de lana bastante estimadas, telas pintadas y que en ella se hace un grande comercio. El Obispo de Barcelona no es sufraganeo de algun otro Obispo y solo en la parte judicial hay apelacion á Tarragona. Pero esto importa poco, y solo sirve para convencer que este habil Encyclopedista equivoca quanto escribe ó copia. ¿Con que Barcelona, esta Ciudad tan celebrada, y la admiracion de todos los extrangeros apreciadores del mérito, es famosa solamente por sus mantas de lana y por sus telas pintadas? ;Ah! ;Si esto fuese una confesion nacional, que sacrilega sería por callar de propio intento la verdad! Pues ¿por qué se la envidia tanto su riqueza de la otra parte de los Pirineos? Si nuestra industria y comercio quedasen aislados en estos dos ramos ¿cómo podria subsistir este prodigioso conjunto de Gremios y Colegios, que forman un sin número de personas? Mr. no sea $\mathrm{Vm}$. tan poco exâcto; confiese á pesar de su afectada ignorancia, que Barcelona, para huir de discusiones, es la Ciudad que posee todo quanto contienen en sí las poblaciones célebres de Europa. En una palabra, no hay Ciudad alguna que tenga un conjunto tan precioso de industria y comercio como esta. Es la Ciudad mas laboriosa de todos los Reynos cultos ${ }^{25}$. En Francia, en Inglaterra y demas Estados, no dudo que algunas Ciudades la adelantarán en ciertos ramos de artefactos y manufacturas; pero no gozarán la universalidad que ella. Diga quanto se le antoje la envidia, que yo no quiero retratar mi proposicion.

Desengañemonos Mr. mio, si Vm. no se instruye mas á fondo de las materias confiadas á su cargo, esa Encyclopedia que es el empeño de los literatos franceses, merecerá muy poca atencion y credito de las demas Naciones. Yo, gracias á Dios, no se el carácter de Vm.; pero me

25 «La platería es excelente; sus obras de vidrio son émulas de las de Valencia; sus obras de acero, y especialmente la cuchillería y todos los instrumentos de cirugía, toda especie de armas, las obras de laton, las fabricas de indianas, colchas, etc. son los objetos en que estriva la riqueza de los vecinos de esta Ciudad, que concurren al consumo universal de España e Indias, y aun à varios Reynos extranjeros [...]. En Barcelona, como en todo el principado, se mira con bochorno al que no trabaja: la inacción está caracterizada de vicio por la opinión y esta ultima adjudica la estimación con entusiasmo à toda persona laboriosa», Encyclopedia metódica, op. cit., p. 260 a, b. 
consta que la recta moral de todo hombre de bien le enseña á usar de mas moderacion con sus próximos.

Ultimamente le declaro ingenuamente, que aunque conozco la debilidad é ingratitud de Vm. y de muchos de sus paisanos en materias que tocan al honor de mi Nacion, soy con todo eso un eterno Panegirista de la suya; conozco la justicia que se la debe, y venero á los hombres doctos, juiciosos y sólidos que ella produce: en una palabra pienso que tal vez es ella en el día la que los tiene en mayor número; pero me tomo la libertad de asegurarle, que ninguno de estos sublimes Monsieures tiene á su inspeccion la Geografia moderna de la Encyclopedia metodica francesa.

¡Ah!... Me he extraviado dirigiendo mi arenga á este buen vecino: error; pero Vms. ya conocen que no lo ha sido de mi voluntad, sino efecto de mi acalorada fantasia. Ahora vuelto ya en mi, les juro que es enteramente de Vms. servidor y amigo, Mariano Berlon. 